https://doi.org/10.15407/ujpe67.1.44

A.E. ZINCHENKO ${ }^{1}$ S.I. SERBIN, ${ }^{2}$ V.Y. CHERNYAK ${ }^{3}$

${ }^{1}$ International Plasma Technology Center, Corp.

(1729 Court Petit, McLean, VA 22101, USA; e-mail: aezms1980@outlook.com)

2 Admiral Makarov National University of Shipbuilding

(9, Heroiv Ukrainy Ave., Mykolaiv 54025, Ukraine)

3 Taras Shevchenko National University of Kyiv

(14A, Lva Tolstoho Str., Kyiv 01004, Ukraine)

\title{
INVESTIGATION OF THE QUENCHING OF NITROGEN OXIDE SYNTHESIS PRODUCTS IN AIR PLASMA
}

\begin{abstract}
The paper presents the results of theoretical and experimental studies of the quenching process of nitrogen oxide synthesis products in a low-temperature air plasma. A developed experimental setup for researching the quenching consists of an air plasma generator with a power of up to $40 \mathrm{~kW}$, as well as a coolant feeding system and control and measuring equipments. For the mathematical modeling of the processes, the numerical solution of the system of differential equations of conservation of mass, momentum, and energy in a turbulent system is used. Calculations and experiments were carried out in the range of variation of the quenching air flow rate $1-5 \mathrm{~g} / \mathrm{s}$ at a plasma power of $31 \mathrm{~kW}$, and a plasma air flow rate of $5 \mathrm{~g} / \mathrm{s}$. The calculated data on the values of heat fluxes are in satisfactory agreement with the experimental values. The theoretically and experimentally obtained value of the average cooling rate of the synthesis products $2.9 \times 10^{5} \mathrm{~K} / \mathrm{s}$ significantly exceeds the cooling rate with traditional water cooling of elements.
\end{abstract}

Ke y w ords: plasma technologies, radio frequency plasma, fixation of nitrogen oxides, quenching, quenching reactor.

\section{Introduction}

There is a growing interest in radio frequency $(\mathrm{RF})$ plasma systems. In some cases, nitrogen gases are obtained by rapidly cooling the air plasma down to room temperature. This is the principle of the plasmachemical method for the fixation of atmospheric nitrogen. One of the features of this method is that nitrogen oxide is thermodynamically unstable at room temperatures, and the slow cooling of nitrous gases causes its decomposition. To avoid this, the rapid gas cooling is used and called the quenching.

(C) A.E. ZINCHENKO, S.I. SERBIN,

V.Y. CHERNYAK, 2022

44
However, high temperatures and the need for the rapid cooling of intermediate and unstable products of plasma-chemical reactions create an urgent need for a more detailed study of such a process as the quenching.

The so-called quenching reactors are mainly wellstudied heat exchangers and are usually limited by the inlet temperature of a cooling medium and the specific heat flux. These limitations offset the benefits of plasma chemical processes. Therefore, the plasma reactors should be studied to intensify the quenching process and to increase the heat transfer efficiency [1]. In addition, they offer the advantages of a simple one-step process and a high density. These char-

ISSN 2071-0194. Ukr. J. Phys. 2022. Vol. 67, No. 1 
acteristics are inherent in fast plasma-chemical reactions [2]. One of the urgent problems is the intensification of the processes of synthesis of nitrogen oxides in air plasma. This problem is associated with the socalled fixation of atmospheric nitrogen. Nitrogen can be bound using both non-equilibrium (non-thermal) and equilibrium (thermal) plasmas. Note, that the plasma processes are considered one of the main priorities in the intensification of various processes and energy savings [3].

The maximum concentration of nitrogen oxides in the air plasma atmospheric pressure corresponds to the temperature interval from 3300 to $3600 \mathrm{~K}[3,4]$.

At temperatures below $2000 \mathrm{~K}$, less than $1 \% \mathrm{NO}$ is formed. As the temperature increases, there is a rapid increase in the $\mathrm{NO}$ concentration to a maximum value of $5.2 \%$ at $3500 \mathrm{~K}$. Above this temperature, the NO concentration decreases to very low values [5].

High quenching rates must be maintained to obtain high levels of nitric oxide concentrations. At the cooling rate of the synthesis products of $10^{4} \mathrm{~K} / \mathrm{s}$, the equilibrium concentration of nitric oxide is maintained by only $47 \%$, while at a cooling rate of $10^{7}$ the product is preserved almost completely [4].

It should be noted that the compliance with a certain law of quenching is also important. For example, if the synthesis of nitric oxide is carried out at a temperature of 4500 to $4700 \mathrm{~K}$, when the equilibrium concentration of oxide is small, you have, firstly, to slowly reduce the temperature down to the optimum level (approximately $3500 \mathrm{~K}$ ) and then to ensure the maximum cooling rate [4].

The high mass average temperature of the RF plasma (from 3000 up to $6000 \mathrm{~K}$ ), the high level of temperature non-uniformity at the exit of the plasma torch, and the mixing of flows, which are sometimes in different physical states, make the development of a quenching reactor quite difficult.

The goal of this work is a theoretical and experimental investigations of the processes of heat transfer and quenching, when mixing the products of synthesis of nitrogen oxides in an air RF plasma with cold gas.

\section{Experimental Setup}

The experimental setup was designed with the purpose to obtain initial data for the modeling and verification of the calculation results. It includes a radio frequency plasma system, quenching reactor, and auxiliary systems for water cooling, gas supply, sampling, and measurement of the $\mathrm{NO}_{x}$ concentration in exhaust gases, as well as an automatic control system.

The main selected criteria for the development are as follows:

- Coordination of geometric dimensions with the output nozzle of the plasma system APT-100-6 of Applied Plasma Technologies, Corp. [6].

- Cooling rate more than $10^{5} \mathrm{~K} / \mathrm{s}$ in the temperature interval from $3600 \mathrm{~K}$ down to $2000 \mathrm{~K}$.

- Uniform temperature distribution at the outlet of the mixing zone with cold gas.

- Maximal water temperature at the output not to exceed $50{ }^{\circ} \mathrm{C}$.

- The reactor surface should not be subjected to local overheating.

- The reactor should be incorporated into the APT-100-6 control system with safe operation and remote control.

The prototype of the plasma-quenching reactor consists of such sequential parts as the quenching section, the main heat exchanger, the output section, and the measuring section.

The quenching section is extremely important for the operation of the entire reactor, as it performs the main, high-speed part of the cooling by mixing the synthesis products with a cold gas. This section is a gas dynamic device, where the transformation of a highly turbulent and not uniform plasma plume into a significantly cooled gas with the most uniform distribution of parameters.

The main heat exchanger performs the function of cooling to such values of temperatures, where the cooling rate is no longer of great importance for the fixation of nitrogen oxides.

The output section is made in the form of a converging cone and serves as a collector for already quenched and cooled to acceptable gas temperatures.

The measuring section consists of a 2 -inch section of pipe, with a gas-sampling probe for chemical analysis, a thermal resistor, and a pressure sensor.

The general view of the site with the quenching reactor is presented in Fig. 1. The reactor is placed vertically on the support structure with the RF plasma torch mounted at the top.

To measure heat fluxes into the walls of quenching reactor elements, temperature and water flow sensors were used. The accuracy of the PT100 resistance tem- 


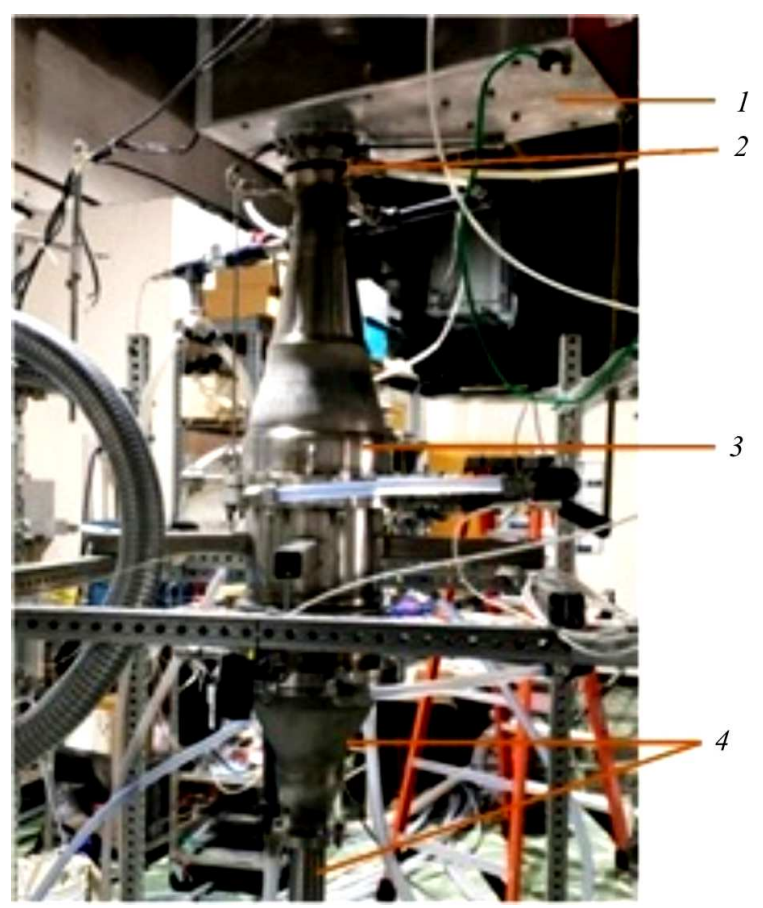

Fig. 1. The quenching reactor is located vertically: plasma torch (1), quenching section (2), main heat exchanger (3), output and measuring sections (4)

perature detector was $\pm 0.5{ }^{\circ} \mathrm{C}$. The accuracy of the RFA-2500 water flow sensor was $\pm 7.0 \%$.

The data were collected in a control system based on an industrial controller Siemens S-1200. Accuracy of the cannel for measuring the PT100 sensor was $\pm 0.2{ }^{\circ} \mathrm{C}$, for measuring the water flow sensor was $\pm 0.3 \%$.

The operation of the quenching reactor was analyzed and tested with an RF plasmatron of the APT100-6 plasma torch system, in which air at a pressure of $0.1 \mathrm{MPa}$ was used as a plasma-forming gas. The products of plasma-chemical reactions are nitrogen oxides (main components: oxide and nitrogen dioxide). The sampled gas was diluted with air in an Environics Series 4000 mixing system to normalize the sample to the measuring range of gas analyzer concentrations. The concentration was measured using a Testo 350-XL gas analyzer, which served as an indicator of the efficiency of the quenching process.

\section{Mathematical Model of the Quenching Section}

The section of quenching is developed as the device with water-cooling walls. The output nozzle of the plasma torch is connected to the "fast" quenching insert through a cylindrical adapter. The adapter may have a swirler to supply the plasma plume with any gases such as air, oxygen, or pre-cooled products of plasma chemical reactions. Behind the "fast" quenching insert are the cylindrical insert and conical expanding section, after which the products are directed to a water heat exchanger to cool down to room temperature.

Radial temperature distributions of the radio frequency plasma torch operating on air were taken at the outlet according to the recommendations $[7,8]$. The mass-average outlet temperatures were determined according to experimental data $[8,9]$. The modeling of physical processes inside the quenching section is based on a solution of the differential equations of mass, momentum, and energy conservation for a turbulent chemically unreactive system [10-15].

The equation of conservation of the mass can be written as follows:

$$
\frac{\delta \rho}{\delta t}+\nabla(\rho \mathbf{v})=0
$$

where $\mathbf{v}$ is the local flow velocity vector, and $\rho$ is the flow density.

The equation of conservation of the momentum reads

$\frac{\delta}{\delta t}(\rho \mathbf{v})+\nabla(\rho \mathbf{v} \mathbf{v})=-\nabla p+\nabla\left(\tau_{\mathrm{st}}\right)+\rho \mathbf{g}+\mathbf{F}$

where $p$ is the static pressure, $\tau_{\text {st }}$ is the stress tensor, $\rho \mathbf{g}$ is the gravitational body force, and $\mathbf{F}$ is the external body forces.

The energy equation has the form:

$$
\begin{aligned}
& \frac{\delta}{\delta t}(\rho E)+\nabla(\mathbf{v}(\rho E+p))= \\
& =\nabla\left(k_{\mathrm{eff}} \nabla T-\sum_{j} J_{j}+\left(\tau_{\mathrm{eff}} \mathbf{v}\right)\right)
\end{aligned}
$$

where $E$ is the total energy, $k_{\text {eff }}$ is the effective conductivity, $J_{j}$ is the diffusion flux of species $j$, and $\tau_{\text {eff }}$ is the effective viscosity coefficient.

For the turbulent flow modeling, the modified RNG $k-\varepsilon$ turbulence model $[9,16,17]$ was used:

$$
\begin{aligned}
& \frac{\delta}{\delta t}(\rho k)+\frac{\delta}{\delta x_{i}}\left(\rho k u_{i}\right)=\frac{\delta}{\delta x_{i}}\left[\left(\alpha_{k} \mu_{\mathrm{eff}}\right) \frac{\delta k}{\delta x_{j}}\right]+ \\
& +G_{k}+G_{b}-\rho \varepsilon-Y_{M}+S_{k}
\end{aligned}
$$




$$
\begin{aligned}
& \frac{\delta}{\delta t}(\rho \varepsilon)+\frac{\delta}{\delta x_{i}}\left(\rho \varepsilon u_{i}\right)=\frac{\delta}{\delta x_{i}}\left[\left(\alpha_{\varepsilon} \mu_{\mathrm{eff}}\right) \frac{\delta \varepsilon}{\delta x_{j}}\right]+ \\
& +C_{1 \varepsilon} \frac{\varepsilon}{k}\left(G_{k}+C_{3 \varepsilon} G_{b}\right)-C_{2 \varepsilon} \rho \frac{\varepsilon^{2}}{k}-R_{\varepsilon}+S_{\varepsilon} . \\
& \mu_{t 0}=C_{\mu} \rho k^{2} / \varepsilon, \mu_{t}=\mu_{t 0} f\left(\alpha_{s}, \Omega, \frac{k}{\varepsilon}\right), \\
& R_{\varepsilon}=\frac{C_{\mu} \rho \eta^{3}\left(1-\eta / \eta_{0}\right)}{1+\beta \eta^{3}} \frac{\varepsilon^{2}}{k}, \eta=S k / \varepsilon .
\end{aligned}
$$

In these equations, $k$ is the turbulence kinetic energy, $\varepsilon$ is the dissipation rate, $\mu_{\text {eff }}$ is the effective viscosity, $G_{k}$ is related to the generation of the turbulence kinetic energy due to velocity gradients, $G_{b}$ corresponds to the generation of a turbulence kinetic energy due to the buoyancy, $Y_{M}$ represents the contribution of the fluctuating dilatation in the case of compressible turbulence to the overall dissipation rate. The quantities $\alpha_{k}$ and $\alpha_{\varepsilon}$ are the inverse effective Prandtl numbers for $k$ and $\varepsilon$, respectively, $S_{k}$ and $S_{\varepsilon}$ are user-defined source terms, $C_{1 \varepsilon}, C_{2 \varepsilon}$, and $C_{3 \varepsilon}$ are the constants of a turbulence model, $\mu_{t 0}$ is the value of the turbulent viscosity calculated without the swirl modification, $\Omega$ is the characteristic swirl number, and $\alpha_{s}$ is the swirl constant.

In the simulation, the constants of the RNG $k-\varepsilon$ turbulence model have been used: $C_{1 \varepsilon}=1.42, C_{2 \varepsilon}=$ $=1.68, C_{\mu}=0.0845, \alpha_{k}=\alpha_{\varepsilon}=1.393, \eta_{0}=4.38$, $\beta=0.012, \alpha_{s}=0.07[16,17]$.

The RNG-based $k-\varepsilon$ turbulence model is derived from the instantaneous Navier-Stokes equations, using a mathematical technique called "renormalization group" (RNG) methods. The analytical derivation results in a model with constants different from those in the standard $k-\varepsilon$ model, and additional terms and functions in the transport equations for $k$ and $\varepsilon$.

In comparison with the standard $k-\varepsilon$ turbulence model, the effect of swirl on turbulence is included in the RNG model, enhancing the accuracy for swirling flows. Moreover, the RNG theory provides an analytically-derived differential formula for effective viscosity that accounts for low-Reynolds-number effects. Thus, the RNG model is more responsive to the effects of rapid strain and streamline curvature than the standard $k-\varepsilon$ model, which explains the superior performance of the RNG model for similar classes of flows.

The calculations used the following boundary conditions:

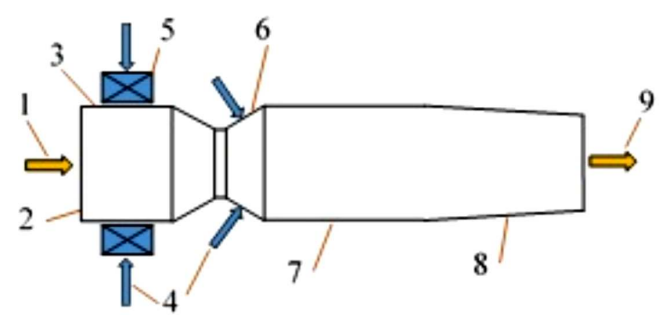

Fig. 2. Schematic diagram of the calculated domain (quenching section): plasma inlet (1), RF plasma torch exit (2), cylindrical adapter (3), air (4), swirler (5), "fast" quenching insert (6), cylindrical insert (7), conical expanding section $(8)$, cooled plasma $(9)$

- at the plasma inlet 1 in Fig. 2: mass flow rate (changes), direction vector, the tangential component of flow direction is 0.3 , the axial component of flow direction is 1.0 , turbulent intensity $5 \%$, turbulent viscosity ratio 10 , thermal: the plasma temperature distribution is non-uniform - profile from [6];

- at the coolant inlet: mass flow rate (changes), 6 holes, velocity normal to the boundary, turbulent intensity $5 \%$, turbulent viscosity ratio 10 , air temperature is constant;

- at the swirling air inlet: flow rate is constant, velocity normal to the boundary, turbulent intensity $5 \%$, turbulent viscosity ratio 10 , air temperature is constant;

- on the all cylindrical and cone wall surfaces: no slip, zero diffusive flux, convection heat transfer coefficient changes: from 200 to $400 \mathrm{~W} /\left(\mathrm{m}^{2} \cdot \mathrm{K}\right)$, wall thickness is $5 \mathrm{~mm}$, the material is stainless steel;

- on the pressure outlet: gauge pressure is 0 , backflow temperature is equal to $300 \mathrm{~K}$, backflow turbulent intensity is $5 \%$.

The assumption was made about the thermal equilibrium of the plasma. The properties of air plasma (density, enthalpy, specific heat, thermal conductivity, laminar viscosity, etc.) are taken from works [18, 19 ] and used in the form of tabulated values. To accelerate the convergence rate of the results, a threedimensional mesh was used, which consists of 482345 polyhedral elements.

The test results of the the cylindrical insert and conical expanding section at a flow rate of plasma forming air of $5 \mathrm{~g} / \mathrm{s}$ and air through a swirler of $0.5 \mathrm{~g} / \mathrm{s}$ are presented in Table.

Three-dimensional calculations of the RF plasma torch were performed using Ansys Fluent software. The calculations were performed for the stationary 


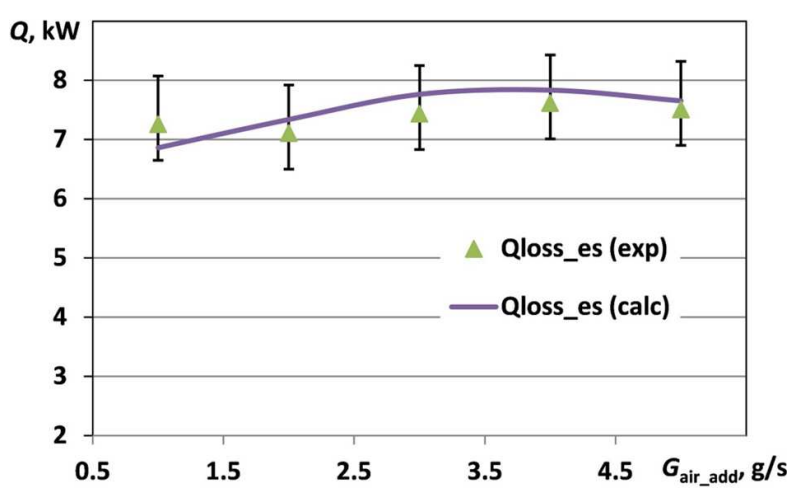

Fig. 3. The value of heat absorbed in the cylindrical insert and conical expanding section at different flow rates of cooling air

mode of operation of the RF plasma torch, which corresponds to $31.34 \mathrm{~kW}$ of thermal power of the plasma plume. Initial conditions: air flow through the plasma torch was $5 \mathrm{~g} / \mathrm{s}$, air flow through the swirler of the cylindrical adapter was $0.5 \mathrm{~g} / \mathrm{s}$ with temperature of $300 \mathrm{~K}$, the mass average temperature of the plasma at the inlet to the quenching section was $3656 \mathrm{~K}$. The flow rate of cooling air for the quenching section of synthesis of nitrogen oxides were 1,3 , and $5 \mathrm{~g} / \mathrm{s}$ with temperature of $300 \mathrm{~K}$, operating pressure was equal to $101325 \mathrm{~Pa}$.

Ansys Fluent software uses a control-volume-based technique to convert a general scalar transport equation to an algebraic equation that can be solved numerically. This control volume technique consists of integrating the transport equation about each control volume, yielding a discrete equation that expresses the conservation law on a control-volume basis [20].

In this study, the well-known pressure-based coupled algorithm solves a coupled system of equations comprising the momentum equations and the pressure-based continuity equation is applied.

The test results

of the investigation of the cylindrical

insert and conical expanding section

\begin{tabular}{|c|c|c|c|}
\hline $\begin{array}{c}\text { Plasma } \\
\text { power, } \\
\mathrm{kW}\end{array}$ & $\begin{array}{c}\text { Mass average } \\
\text { plasma } \\
\text { temperature, } \mathrm{K}\end{array}$ & $\begin{array}{c}\text { Cooling air } \\
\text { flow rate, } \\
\text { rate, } \mathrm{g} / \mathrm{s}\end{array}$ & $\begin{array}{c}\text { Absorbed } \\
\text { heat, } \\
\mathrm{kW}\end{array}$ \\
\hline 31.31 & 3664 & 1 & 7.25 \\
31.32 & 3686 & 2 & 7.10 \\
31.38 & 3693 & 3 & 7.43 \\
31.54 & 3712 & 4 & 7.61 \\
31.31 & 3685 & 5 & 7.56 \\
\hline
\end{tabular}

Since the momentum and continuity equations are solved in a closely coupled manner, the rate of solution convergence significantly improves when compared to the segregated algorithm. However, the memory requirement increases by $1.5-2$ times that of the segregated algorithm since the discrete system of all momentum and pressure-based continuity equations needs to be stored in the memory when solving for the velocity and pressure fields (rather than just a single equation, as is the case with the segregated algorithm) [20].

To increase the stability of the numerical solution in the presented study, we used: the pressure-velocity coupling solution methods, the SIMPLE first order upwind numerical scheme, as well as under-relaxation factors for pressure $=0.2$, for momentum $=0.7$, for turbulent kinetic energy and specific dissipation rate $=0.8$.

Convergence absolute criteria for the continuity equation was 0.0005 ; for the velocity component equations were 0.0005 ; for the energy equation was 1e-08; for characteristics of turbulence $k$ and $\varepsilon$ were 0.0005. Under such conditions, typical root mean square (RMS) residuals to establish the solution convergence are about $1 \mathrm{e}-4$.

To simplify the calculations of the heat transfer to the walls of the flow modifier, only convection processes were taken into account. Even though radiant heat transfer was not taken into account in the calculations, but the obtained data can be considered qualitatively correct and reflect the trends in changing the defining parameters.

Figure 3 shows the experimental and calculated values of heat absorbed in the walls of the cylindrical insert and conical expanding section at stationary operating mode. A sufficiently high level of error in measuring the heat flux is determined by the instability of the plasma plume position due to turbulent pulsations and a long time for the quenching device to reach a stationary mode.

It can be seen that the amount of heat absorbed by the wall depends little on the flow rate of the cooling air. This is due to the predominant share of heat emitted by the air plasma plume before the "fast" quenching insert in the total heat flux into the wall.

Figures 4 and 5 show the temperature and velocity contours in the longitudinal section of the quenching section at different cooling air flow rates.

ISSN 2071-0194. Ukr. J. Phys. 2022. Vol. 67, No. 1 

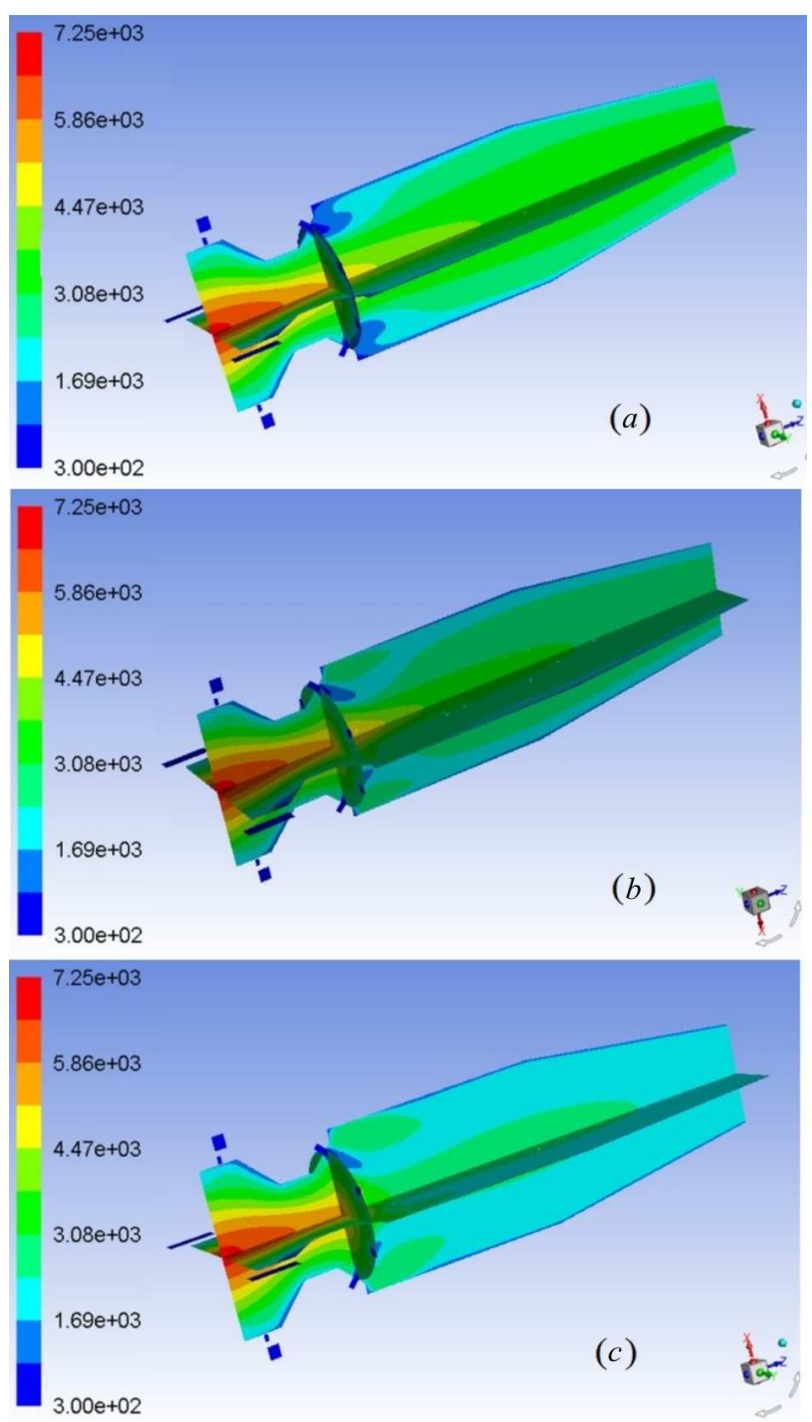

Fig. 4. Temperature distribution (K) for different air cooling flow rates: $1 \mathrm{~g} / \mathrm{s}(a), 3 \mathrm{~g} / \mathrm{s}(b), 5 \mathrm{~g} / \mathrm{s}(c)$

With an increase in the flow rate of cooling air from $1 \mathrm{~g} / \mathrm{s}$ to $5 \mathrm{~g} / \mathrm{s}$, the depth of its penetration into the "fast" quenching insert increases (Fig. 5). This leads to an improvement in the quality of mixing of the air plasma jet with a cooler and a more significant drop in the temperature of the flow (Fig. 4) in its axial part.

The radial distribution of the flow temperature at the outlet of the quenching section for three values of air cooling flow rate is shown in Fig. 6. It is obvious that despite the significant equalization of ISSN 2071-0194. Ukr. J. Phys. 2022. Vol. 67, No. 1
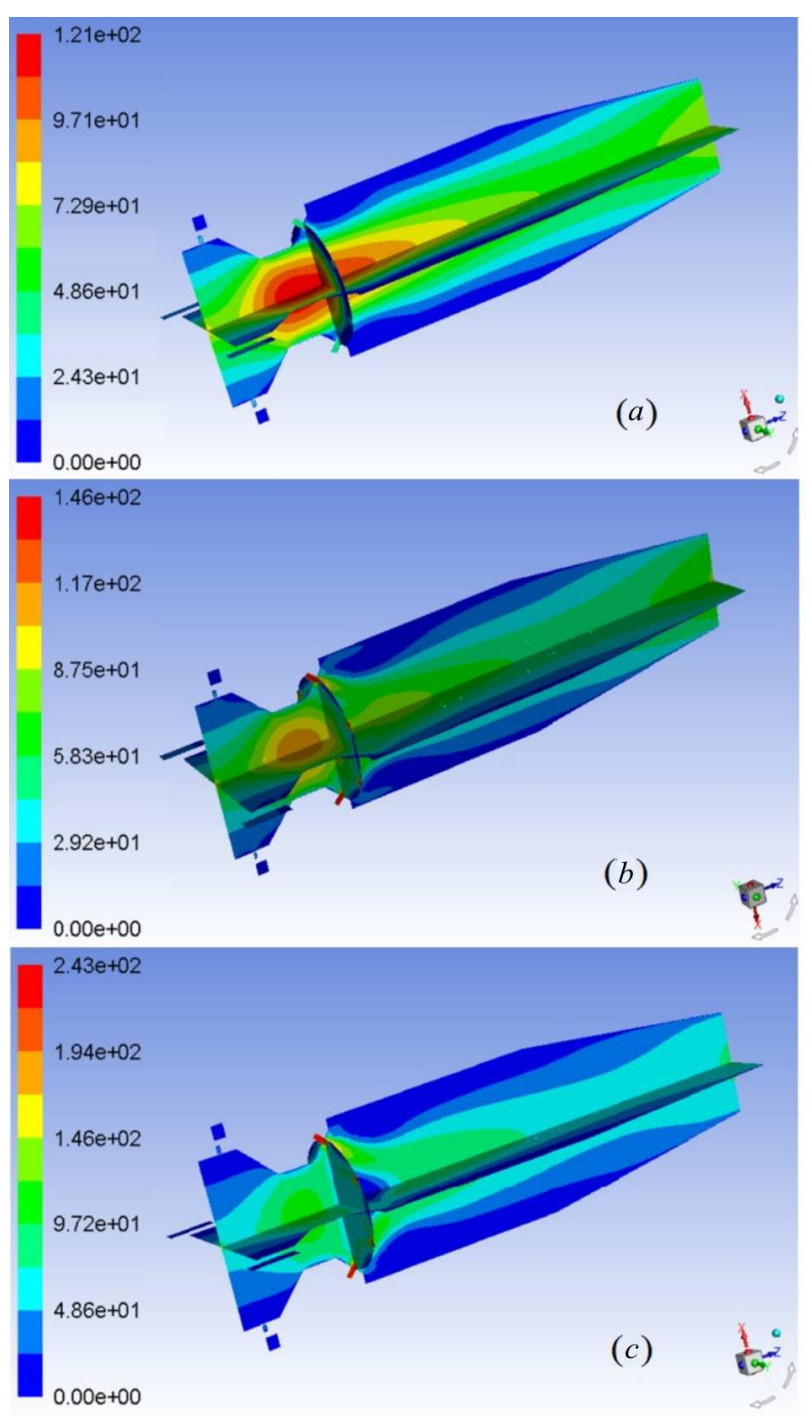

Fig. 5. Velocity magnitude distribution $(\mathrm{m} / \mathrm{s})$ for different air cooling flow rates: $1 \mathrm{~g} / \mathrm{s}(a), 3 \mathrm{~g} / \mathrm{s}(b), 5 \mathrm{~g} / \mathrm{s}(c)$

the flow temperature at the outlet of the quenching section, there are areas with elevated temperatures. These inhomogeneities should be taken into consideration when designing the section of the main heat exchanger of the quenching reactor.

The coefficient of temperature non-uniformity at the outlet of the quenching section was calculated as follows:

$\sigma=\left(T_{\max }-T_{\mathrm{av}}\right) / T_{\max }$,

where $T_{\max }$ and $T_{\mathrm{av}}$ are the maximum and average temperatures at the outlet of the quenching section. 


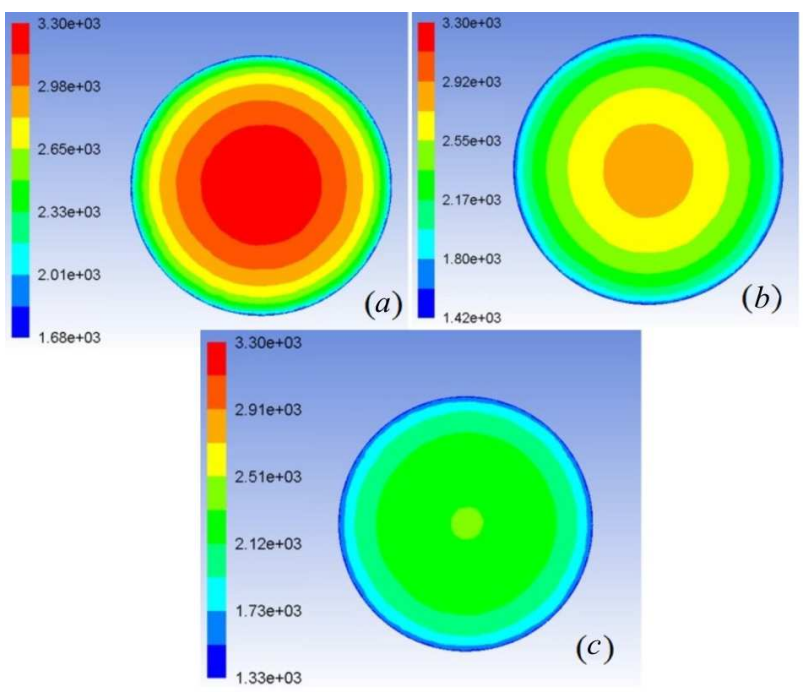

Fig. 6. Radial temperature distribution $(\mathrm{K})$ for different air cooling flow rates: $1 \mathrm{~g} / \mathrm{s}(a), 3 \mathrm{~g} / \mathrm{s}(b), 5 \mathrm{~g} / \mathrm{s}(c)$

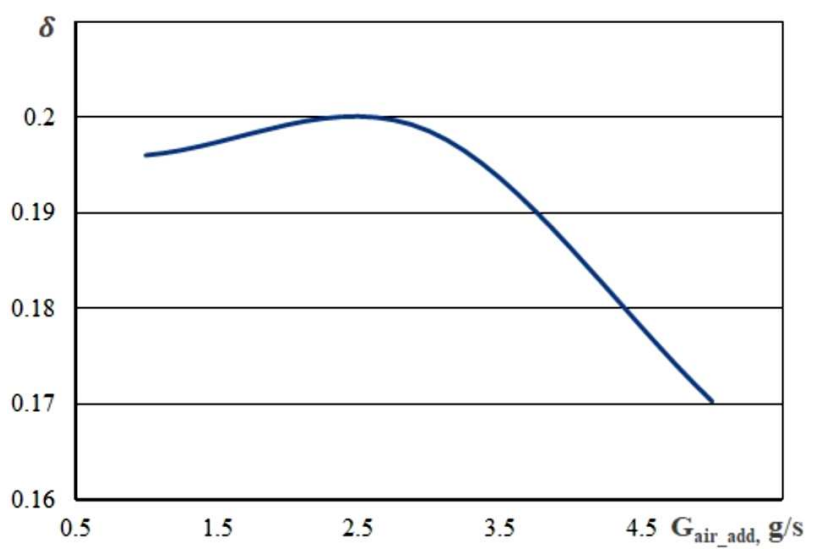

Fig. 7. Dependences of coefficient of temperature non-uniformity on the flow rate of cooling air

Figure 7 shows the dependence of the coefficient of temperature non-uniformity at the outlet of the quenching section depending on the flow of cooling air. With the increasing flow rate of cooling air, the flow temperature in the cross-section of the outlet nozzle of the quenching section is equalized. Thus, at air flow rates of 1,3 , and $5 \mathrm{~g} / \mathrm{s}$ the calculated coefficient of non-uniformity was $0.196,0.198$, and 0.171 , respectively.

The distribution of velocity vectors within the quenching section depending on the flow rate of cooling air is shown in Fig. 8.
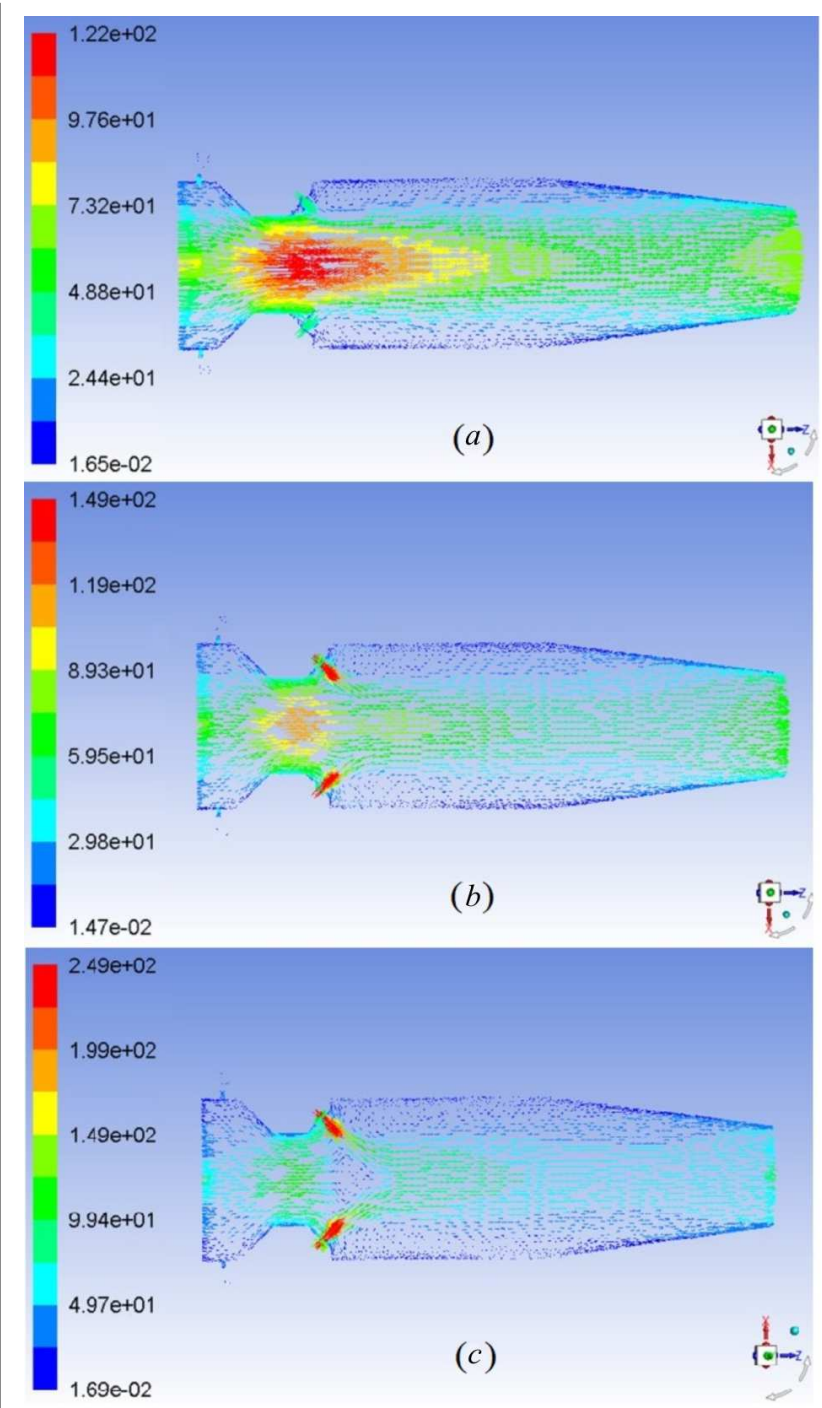

Fig. 8. Velocity vectors $(\mathrm{m} / \mathrm{s})$ in the quenching section for different air cooling flow rates: $1 \mathrm{~g} / \mathrm{s}(a), 3 \mathrm{~g} / \mathrm{s}(b), 5 \mathrm{~g} / \mathrm{s}(c)$

Note that the cooling air is supplied through 4 evenly spaced holes in the "fast" quenching insert. At a cooling air flow rate of $1 \mathrm{~g} / \mathrm{s}$, the maximum velocities take place in the axial section at the inlet to the "fast" quenching insert (Fig. 8). At a cooling air flow rate of $5 \mathrm{~g} / \mathrm{s}$, the maximum velocities take place in the holes. In this case, the velocity vectors are transformed, and the jets of cooling air begin to play the role of bluff bodies (obstacles) for the plasma flow.

It is obvious that, with increasing air flow for quenching, the total flow rate through in the quenching section increase. At a maximum cooling air flow

ISSN 2071-0194. Ukr. J. Phys. 2022. Vol. 67, No. 1 
rate of $5 \mathrm{~g} / \mathrm{s}$ in the cross-section of its supply to the quenching section, a low velocity zone is formed. This zone displaces the plasma flow from the plasma torch to the cooling air supply enters, thereby increasing the velocity and creating conditions for the best mixing of "hot" flow with quenching air.

Figure 9 shows the dependences of the average mass temperatures at the outlet of the quenching section on the flow rate of cooling air. It is necessary to clarify that the average mass temperature is the temperature that corresponds to the average enthalpy in the selected cell zone based on mass averaging. Temperatures were calculated by two methods: by quenching data using the heat balance and by the 3D modeling.

With an increase in the flow rate of the cooling air due to the dilution of the plasma jet (mixing of the plume with the cooling air), the flow temperature decreases, despite the almost constant heat fluxes into the wall. Thus, a decrease in temperature occurs both due to the use of water cooling of the walls, and when the plasma is mixed with a cooler. At a cooling air flow rate of $5 \mathrm{~g} / \mathrm{s}$, the flow temperature becomes equal to $2000 \mathrm{~K}$ and the main reactions of nitrogen fixation are practically completed [5]. After that, a surface-type water cooler is used to cool the products.

Note that no direct measurement of the plasma flow temperatures was performed. The temperatures were determined either numerically using Ansys Fluent software: Tout es(calc), or using the heat balance equation and experimental data on absorbed walls heat: Tout_es(balance_exp). In the last case, the value of the enthalpy of the flow was found and then the average value of the temperature was determined using the tabular data from [18].

The errors of indirect measurements, in particular, the temperature and quenching rate, were determined by the form of their functional dependences on the results of direct measurements. The average relative errors in determining these values were $\pm 8.2 \%$ and $\pm 11.3 \%$, respectively.

The rate of quenching plays one of the key roles in the organization of such technological process as plasma fixation of nitrogen oxides from the air. The average quenching rate was calculated by the following formula:

$V_{g}=\left(T_{\text {esIn }}-T_{\text {esOut }}\right) / L_{\text {es }} /\left(V_{\text {axIn }}+V_{\text {axOut }}\right) / 2$,

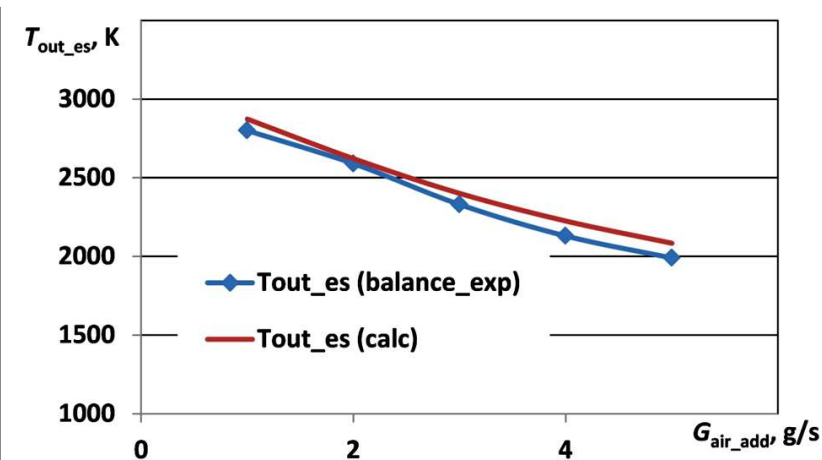

Fig. 9. Dependences of the average mass temperatures at the outlet of the quenching section on the flow rate of cooling air

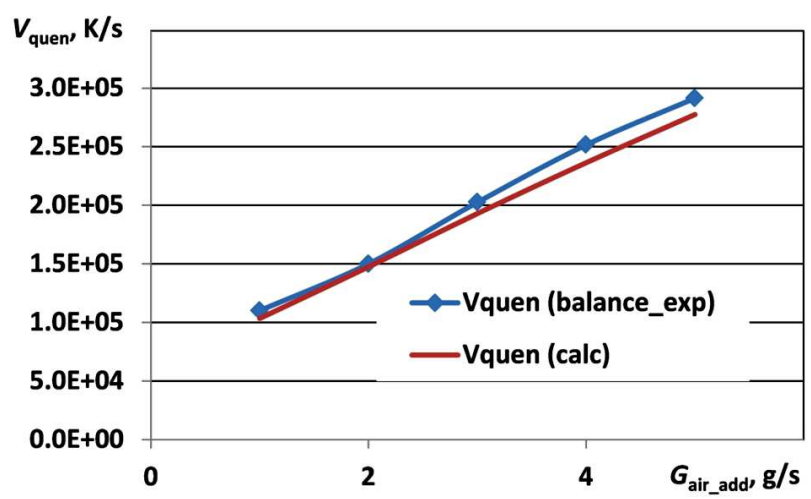

Fig. 10. Dependences of average quenching rates on cooling air flow rate

where $T_{\text {esIn }}$ and $T_{\text {esOut }}$ are the mass average flow temperatures at the inlet and outlet of the quenching section, $L_{\mathrm{es}}$ is the length of quenching section, $V_{\mathrm{axIn}}$ and $V_{\text {axOut }}$ are the axial flow velocity components at the inlet and outlet of the quenching section.

A comparison of the results of calculations and experiments is shown in Fig. 10.

It can be seen that, with an increase in the cooling air flow rate from $1 \mathrm{~g} / \mathrm{s}$ to $5 \mathrm{~g} / \mathrm{s}$, the quenching rate increases approximately threefold and reaches $2.9 \times 10^{5} \mathrm{~K} / \mathrm{s}$. This value is several times higher than the quenching rates of $5.22 \times 10^{3}-4.43 \times 10^{4}$ [21], previously achieved using only water cooling, and brings the expected output concentrations of nitrogen oxides closer to the theoretical values determined by the Zeldovich mechanism.

Preliminary measurements of the concentration of nitrogen oxides $\mathrm{NO}_{x}$ at the outlet of the quenching section at achieved quenching rate of $2.9 \times 10^{5} \mathrm{~K} / \mathrm{s}$ gave a concentration value of almost $7 \%$ (by weight) 
at 1 bar pressure, which is a very good indicator. Note that this value of nitrogen oxides content exceeds the maximum concentrations of nitrogen oxides achieved using various plasma technologies: $0.63 \%$ (spark), $0.6 \%$ (DBD), $0.938 \%$ (microwave), $1.45 \%$ (gliding arc), $1.5 \%$ (plasmatron), $5.5 \%$ (rotating gliding arc) [22]. Note that all mentioned in literature data were obtained on a laboratory bench with the flow rate of a working medium by 2 orders of magnitude less than in present experiments.

\section{Conclusions}

1. The quenching of products of the synthesis of nitrogen oxides in a radio frequency air plasma due to the mixing with a cold gas is considered.

2. Three-dimensional CFD calculations were used to determine the temperature distribution and velocities along the flow path of the quenching section.

3. A comparison of results of the numerical analysis with data from the physical experiment shows that the results are satisfactory. For a more accurate prediction of the energy exchange patterns in the quenching reactor effects of the plasma plume radiation must be considered.

4. The maximum experimental cooling rate of synthesis products by the mixing with a cold gas in the section of "fast" quenching is $2.9 \times 10^{5} \mathrm{~K} / \mathrm{s}$, which is an order of magnitude higher than the cooling rate of the quenching reactor with water cooling [21], but not optimal $\left(10^{7} \mathrm{~K} / \mathrm{s}\right)[4]$.

5 . One of the ways to increase the concentrations of nitrogen oxide synthesis products is to increase the quenching rate due to the additional injection of cooling media, as well as to optimize the profile of the output nozzle of the plasma torch to increase the flow rate.

6. The obtained results can be used in the design of various technological processes where high speed of quenching is required.

1. B.S. Patil, V. Hessel, J. Lang, Q. Wang. Plasma-assisted nitrogen fixation reactions. In: Alternative Energy Sources for Green Chemistry (2016), Ch. 10, pp. 296-338.

2. B.S. Patil, Q. Wang, V. Hessel, J. Lang. Plasma N2-fixation: 1900-2014. Catalysis Today 256, 49 (2015).

3. I.B. Matveev, S.I. Serbin. Synthesis of nitrogen oxides in ICP/RF plasma. IEEE Trans. Plasma Sci. 47 (1), 47 (2019).
4. Fixation of Atmospheric Nitrogen in the RF Plasma Torch (Tomsk Institute of Physics and Technology, 2016) (in Russian).

5. L.S. Polak, F.B. Vurzel, A.A. Ovsyannikov. Plasma Use in Chemical Processes (Mir, 1970) [in Russian].

6. Applied Plasma Technologies. The new millennium tools [http://www.plasmacombustion.com/product-torches.html].

7. I.B. Matveev, S.I. Serbin. A multitorch RF plasma system as a way to improve temperature uniformity for high power applications. IEEE Trans. Plasma Sci. 48 (2), 332 (2020).

8. S.V. Dresvin, D.V. Ivanov. Modeling of the processes describing plasma behavior in the torches. In: Plasma Assisted Combustion, Gasification, and Pollution Control. Vol. 1. Methods of Plasma Generation for PAC. Chief editor I. Matveev, 422 (Outskirts Press, 2013).

9. I.B. Matveev. Plasma Assisted Combustion, Gasification, and Pollution Control. Vol. 2. Combustion and Gasification (Outskirts Press, 2015).

10. I. Matveev, S. Serbin. Experimental and numerical definition of the reverse vortex combustor parameters. In: 44th AIAA Aerospace Sciences Meeting and Exhibit 6662 (Reno Nevada, 2006).

11. I. Matveev, S. Serbin, A. Mostipanenko. Numerical optimization of the "tornado" combustor aerodynamic parameters. In: 45th AIAA Aerospace Sciences Meeting and Exhibit (Reno Nevada, 2007).

12. I. Matveev, S. Matveeva, S. Serbin. Design and Preliminary Test Results of the Plasma Assisted Tornado Combustor. In: Collection of Technical Papers-43rd AIAA/ASME/SAE/ASEE Joint Propulsion Conference 6, 6091 (Cincinnati OH, 2007).

13. I. Matveev, S. Serbin. Investigation of a reverse-vortex plasma assisted combustion system. In: Proc. of the ASME 2012 Heat Transfer Summer Conf. 133 (Puerto Rico USA, 2012).

14. I.B. Matveev, S.I. Serbin, N.V. Washchilenko. Sewage sludgeto-power. IEEE Trans. Plasma Sci. 42 (12), 3876 (2014).

15. I.B. Matveev, S.I. Serbin, N.V. Washchilenko. Plasmaassisted treatment of sewage sludge. IEEE Trans. Plasma Sci. 44 (12), 3023 (2016).

16. B.E. Launder, D.B. Spalding. Lectures in Mathematical Models of Turbulence (Academic Press, 1972).

17. D. Choudhury. Introduction to the Renormalization Group Method and Turbulence Modeling. Fluent Inc. Technical Memorandum TM-107 (1993).

18. V.S. Engelsht, V.C. Gurovich, G.A. Desjatnikov. Low Temperature Plasma. Vol. 1. The Theory of Electric Arc Column (Novosibirsk Nauka, 1990) [in Russian] [ISBN: 502-029297-4].

19. V.D. Parchomenko, P.I. Soroka, Yu.I. Krasnokutskiy. Low Temperature Plasma. Vol. 4. Plasma Chemical Technology (Novosibirsk Nauka, 1991) [in Russian].

20. Ansys Fluent Fluid Simulation Software [https:// www.ansys.com/products/fluids/ansys-fluent].

ISSN 2071-0194. Ukr. J. Phys. 2022. Vol. 67, No. 1 
21. I.B. Matveev, S.I. Serbin, A.E. Zinchenko. A high temperature quenching reactor. IEEE Trans. Plasma Sci. 49 (3), 984 (2021).

22. H. Chen, D. Yuan, A. Wul, X. Lin, X. Li. Review of lowtemperature plasma nitrogen fixation technology. Waste Disposal \& Sustainable Energy. 3, 201 (2021).

Received 19.04.21

А.Є. Зінченко, С.І. Сербін, В.Я. Черняк

ДОСЛІДЖЕННЯ ПРОЦЕСУ

ГАРТУВАННЯ ПРОДУКТІВ СИНТЕЗУ

ОКСИДІВ АЗОТУ В ПОВІТРЯНІЙ ПЛАЗМІ

У статті представлені результати теоретичних та експериментальних досліджень процесу загартування продуктів синтезу оксиду азоту в низькотемпературній повітряній плазмі. Розроблено експериментальну установку для дослідження процесів гарту, що складається з повітряного гене- ратора плазми потужністю до 40 кВт, а також системи подачі охолоджуючої рідини та контрольно-вимірювального обладнання. Для математичного моделювання процесів використовується чисельний розв'язок системи диференційних рівнянь збереження маси, імпульсу та енергії в турбулентній системі. Розрахунки та експерименти проводились у діапазоні змін швидкості потоку охолоджуючого повітря 1-5 г/с при потужності плазми 31 кВт і швидкості потоку повітря плазми 5 г/с. Розраховані дані про значення теплових потоків задовільно узгоджуються з експериментальними значеннями. Теоретично та експериментально отримане значення середньої швидкості охолодження продуктів синтезу $2,9 \cdot 10^{5} \mathrm{~K} / \mathrm{c}$ значно перевищує швидкість охолодження при традиційному водяному охолодженні елементів.

Ключов $i$ слова: плазмові технології, високочастотна плазма, фіксація оксидів азоту, гартування, гартівний реактор. 